\title{
Benestent II: Back to the Future
}

\author{
HÅKAn EMANUELSSON, M.D., Ph.D., ${ }^{*}$ WILlEM J. van der GIESSEN, M.D., Ph.D., ${ }^{* *}$ \\ and PATRICK W. SERRUYS, M.D., Ph.D., ${ }^{* *}$ ON BEHALF OF THE BENESTENT GROUP $\dagger$ \\ From the *Division of Cardiology, Sahlgrenska University Hospital, Göteborg, Sweden; and the **Thoraxcenter, Erasmus University \\ Rotterdam, Rotterdam, The Netherlands
}

\section{Introduction}

In spite of advances in our knowledge to use coronary stents, there are still limitations to general applicability of the technique. Mechanical stiffness and thrombogenicity necessitating multidrug anticoagulation therapy are the most important problems. ${ }^{1,2}$ Therefore, further research to improve the currently available devices is needed. At the present time, there is no consensus regarding the optimal stent design, or what surface should be used to achieve suitable properties with regard to prevention of thrombus formation and reactive vessel wall proliferation.

The Benestent I trial, a multicenter randomized study comparing the safety and efficacy of primary Palmaz-Schatz stent implantation versus percutaneous transluminal coronary angioplasty (PTCA) in patients with stable angina pectoris and a single de novo lesion in a native coronary artery, has very recently been completed. ${ }^{3}$ This study demonstrated that event-free survival was higher in patients who received a stent compared to patients treated with P'TCA (67\% vs 55\%) at 6-month follow-up. This was largely due to a reduction of repeat revascularization in patients treated with a stent, caused mainly by a significantly lower restenosis rate in the stented group ( $22 \%$ vs $32 \%$ ). However, the incidence of vascular complications (bleeding episodes or pseudoaneurysm formation at the puncture

$\uparrow$ See Appendix.

Address for reprints: Håkan Emanuelsson, M.D., Ph.D., Division of Cardiology, Sahlgrenska University Hospital, S-413 45 Göteborg, Sweden.

Submitted for publication August 23, 1994; accepted for publication August 26, 1994. site) and subacute coronary thrombosis was increased after stenting, reflecting the difficult balance between the thrombogenicity of the stent and the need for an intensive anticoagulation regimen.

In order to further improve the clinical results of coronary stenting, we have directed our attention to coating the stent with material that would minimize the risk of abrupt stent closure and, thereby, allow reduction of anticoagulation therapy. To that purpose, a heparin-coated stent has been developed and tested in an animal model. In the following, a short description will be given of the principles of the heparin coating. Furthermore, the result of the animal studies will be summarized. Finally, the design of the pilot phase of the Benestent II study, an open, noncontrolled registry using a heparin-coated stent, will be outlined.

\section{Principles of Heparin Coating}

Blood compatibility is a critical requirement for intravascular devices, since contact of blood with a foreign surface will commonly result in deposition and activation of plasma proteins, platelets, and other cellular elements, leading to thrombus formation. During decades, there has been intensive research in the area of blood-compatible materials for noncoronary purposes. ${ }^{4}$ Instead of introducing a foreign material directly into a blood vessel, material surface modifications with improved properties with regard to blood and tissue compatibility appear to be a viable approach. It has been shown that heparin-like molecules with anticoagulant activity are synthesized on the luminal surface of endothelial cells. ${ }^{5,6}$ Indeed, the endothelium plays an important part in the inactivation of 
thrombin and possibly also other coagulation factors. Not unexpectedly. therefore. heparin has been one of the most extensively explored substances for adsorption or binding to biomaterial surfaces. Heparin-coated surfaces have been evaluated in various types of devices where thromboresistance might be of particular clinical value. e.g., arteriovenous shunts, catheters. ar- terial filters, oxygenators, cardiopulmonary bypass circuits, and vascular endoprostheses. ${ }^{7-11}$

The principal anticoagulant mechanism of heparin is mediated by its interaction with antithrombin III. This complex accelerates the inactivation of thrombin and other coagulation factors. It has been shown that the active site of heparin contains a specific carbohy-

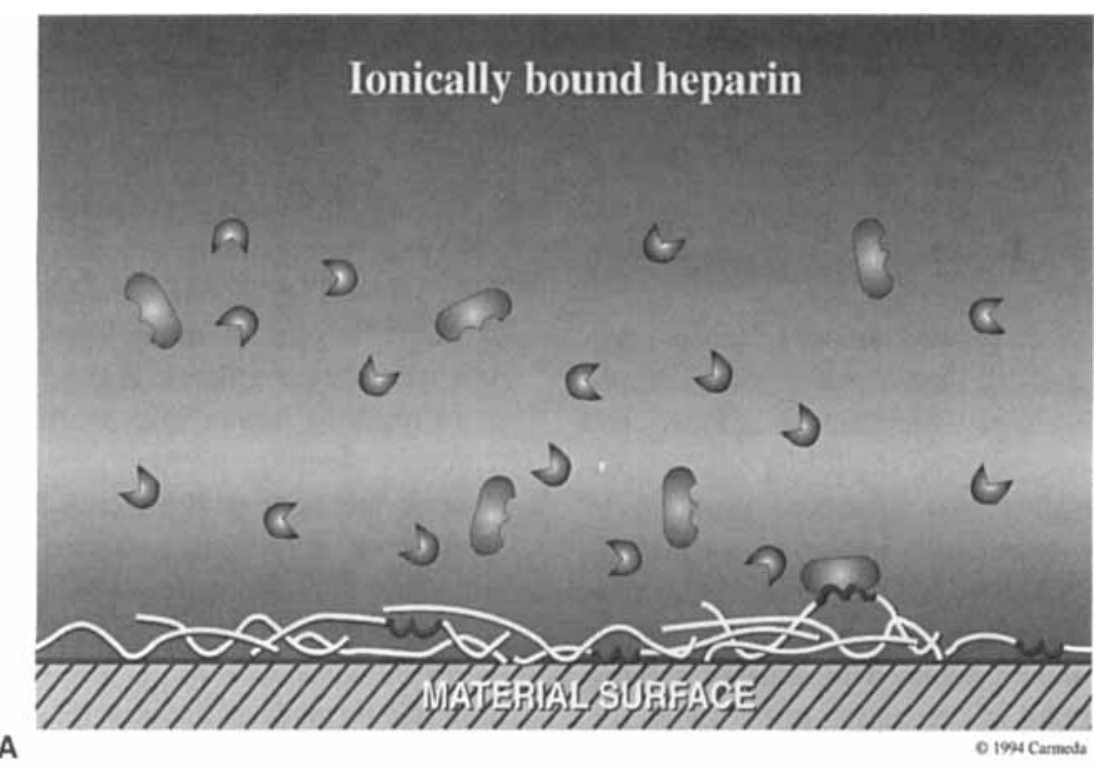

A

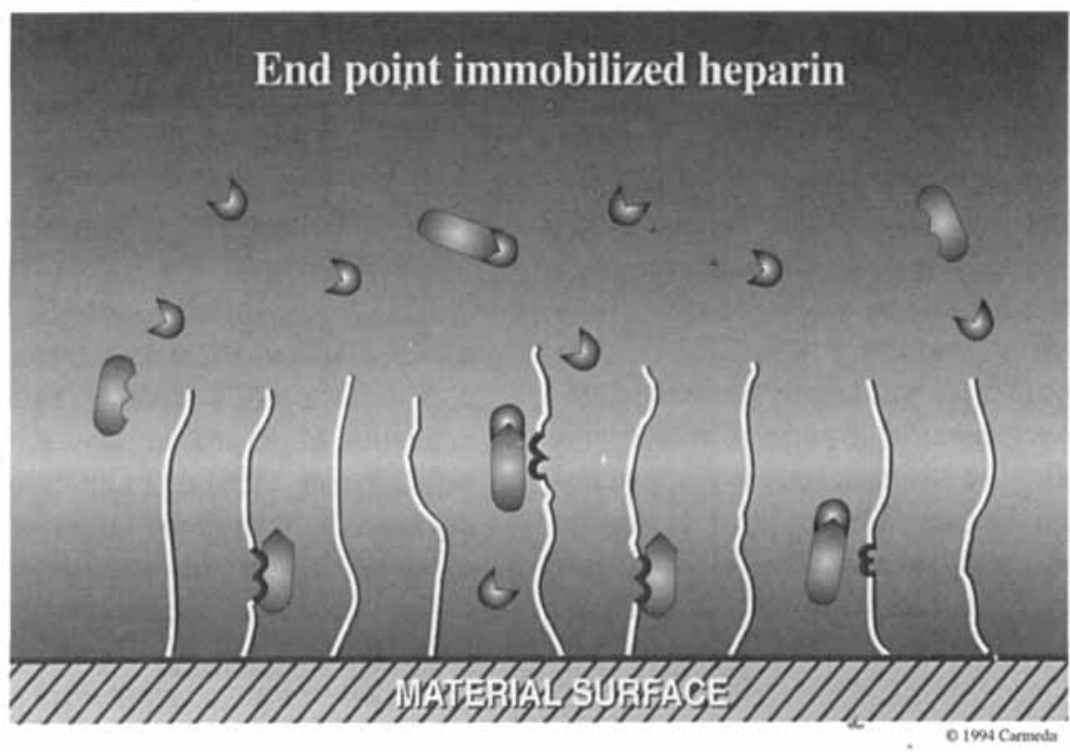

Figure 1. Schematic illustration of method for heparinization of surfaces. Note that the active cartoh drate sequence of heparin has the most uptimal orientation for interaction with components of the hlond, where the molecules are end attached and perpendicular to the surface. Large symbols: antithrombin III: small s.mbols: thrombin. (Permission from Carmeda AB. Stockholm. Sweden.) 


\section{BENESTENT II}

Table 1. Methods for Heparin-Coating of Biomaterials

\begin{tabular}{ll}
\hline Physically & - Adsorbed into matric coating \\
immobilized & heparin block copolymer \\
Ionically bonded & - Benzalkonium vinyl alcohol \\
Covalent coupled & - Mid-point attached albumin-heparin \\
& end-point attached heparin \\
\hline
\end{tabular}

drate sequence. ${ }^{12-14}$ Obviously, when the heparin molecule is modified in the process of surface coating, it is essential that the active sequence responsible for anticoagulation remains unaltered.

There are various methods of binding heparin to a surface (Table 1). The simplest solution is adsorbing a heparin solution to the biomaterial surface. ${ }^{19-21,36} \mathrm{~A}$ problem with this type of heparin coating is the lack of control of the rate of release. The heparin molecule contains a large number of negatively charged groups, and may, therefore, be ionically or electrostatically bound to surfaces with positive charges (Fig. 1A). ${ }^{15-18}$ Heparin may also be covalently bonded, but this requires the development of specific chemistry between the heparin and the surface. ${ }^{22-26,35}$

Covalently Bonded Heparin. The aim of immobilization of heparin is to achieve endothelium-like thromboresistant properties of the surface. There is no general method available for heparin binding on all types of material used in medical devices. Since heparin is a highly charged and hydrophilic polymer, the binding has to be prepared by pretreatment of the surface to be coated with reactive groups ("functionalizing"). Obviously, this procedure will be more complicated if the device is composed of several materials that differ in chemical properties and surface characteristics. This problem does not play a role in the coating of current metallic stents.

In the early development of heparin coatings, a reduction in heparin activity was frequently observed when the molecules were covalently attached to the surface, probably due to alteration of the active carbohydrate sequence during the linking process. ${ }^{27}$ This problem was circumvented when heparin could be coupled by end point attachment (Fig. 1B). ${ }^{26,28}$ The first step in this procedure was partial degradation of heparin with nitrous acid, creating reactive aldehyde groups in the reducing terminal residues. It was shown by Larm et al. ${ }^{26}$ in 1983 that heparin fragments could be immobilized by end point attachment on materials coated with polyethylenimine. The aldehyde groups were subsequently coupled to the aminated surface by reductive amination (Fig. 2). By this method, the active carbohydrate sequence of the heparin molecule can be preserved functionally intact throughout the coupling reaction.
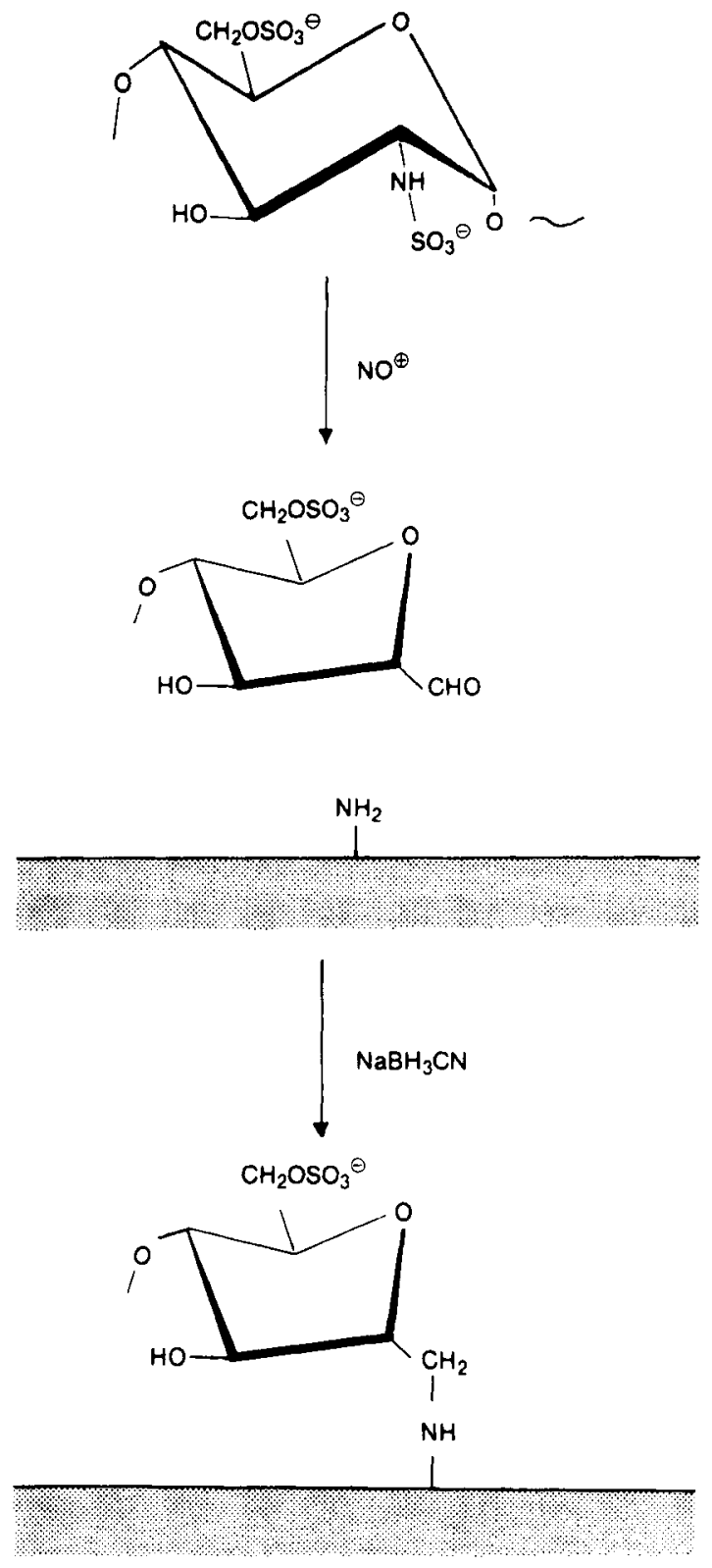

Figure 2. Endpoint attachment by covalent coupling of partially nitrous acid degraded heparin to aminated surfaces. (Permission from Hoffman J, Larm O, Scholander E. A new method for covalent coupling of heparin and other glycosaminoglycans to substances containing primary amino groups. Carbohydr Res 1983;117: 328-331.) 
In addition to being compatible with the plasma coagulation system, a thromboresistant surface should not promote adhesion and activation of platelets and leukocytes. Since heparin has been reported to induce platelet activation, ${ }^{29}$ this consequence might be expected with surface immobilized heparin as well. However, it has been shown that in comparison to uncoated material, the surface with end point attached heparin on a high molecular weight polyamine stabilized with glutaraldehyde, was highly compatible with platelets as well as granulocytes and macrophages. ${ }^{30-32}$

The principle of perpendicularly oriented. end attached, covalently bound and immobilized heparin molecules on a polymer surface (Carmeda Bioactive Surface. Carmeda AB. Stockholm) was considered the best candidate for coating of coronary stents. Pilot in vitro studies performed with stents coated with this surface demonstrated that the mounting on the balloon catheters and subsequent expansion of the stents did not affect the heparin activity. In contrast, sterilization with heat or ethylene oxide reduced the heparin activity considerably $(50 \%-70 \%$ loss). Consequently, for initial studies, the stents were coated under aseptic conditions or with higher concentrations of heparin to compensate for the loss of heparin activity during ethylene oxide sterilization.

\section{Results from Animal Experiments}

Palmaz Schatz ${ }^{\text {TM }}$ stents were implanted in four groups of nonatherosclerotic pigs $(n=35$ ). Using the diameter of the guiding catheter as a reference, a segment with a diameter of $2.5-3.5 \mathrm{~mm}$ was selected in the left anterior descending coronary artery using online quantitative coronary arteriography. ${ }^{33}$ Thereafter, either a heparin-coated or a conventional uncoated stent (in alternate order) was positioned at the site preselected for implantation. ${ }^{34}$ Postprocedure, 15 animals did not receive antithrombotic prophylaxis, whereas the remaining 20 pigs were administered $300-\mathrm{mg}$ aspirin orally starting the day before implantation, and this treatment was continued during the 28 days of follow-up.

After 4 weeks, coronary angiography was performed on all surviving animals using the same projection as during implantation. Thereafter, the thorax was opened by a mid-sternal split, and a lethal dose of sodium pentobarbital was injected intravenously im- mediately followed by cross-clamping of the ascending aorta. The heart was excised after pressure infusion (120 $\mathrm{mmHg}$ ) of $500 \mathrm{cc}$ of saline followed by $500 \mathrm{cc}$ of buffered formaldehyde and the coronary arteries were dissected from the epicardial surface. The stented and adjacent segments were then placed in $4 \%$ formaldehyde in phosphate buffer for at least 48 hours in preparation for microscopy. After fixation, the stented segments were processed for light microscopical examination. Hematoxilin-azaphloxin was used as a routine stain while resorcin-fuchsin was used as an elastic stain.

Results. In the 15 animals without aspirin treatment, the thrombotic occlusion rate within 48 hours was $33 \%$. There were no differences in patency observed between the coated and the conventional stents. In the animals receiving aspirin there were four stent occlusions in the control group (40\%), but none in the group with coated stents $(\mathrm{P}<0.05)$.

In conclusion, the demonstration of thromboresistance of heparin-coated stents in aspirin treated pigs was considered encouraging and created the basis for the subsequent phase of stent implantation in humans.

\section{Benestent II Trial-Pilot Phase}

The Benestent II study is an open, multicenter, nonrandomized, prospective registry specifically designed to evaluate the safety of elective implantation of a heparin-coated Palmaz Schatz ${ }^{\text {IM }}$ stent in patients with angina pectoris and a single de novo lesion in a native coronary artery (similar patient population as in Benestent I study). The primary objective of implanting heparin-coated coronary stents in humans is to determine the incidence of acute and subacute thrombotic stent occlusion and the incidence, location, and severity of vascular and bleeding complications during hospital stay and within 30 days. Furthermore, the occurrence of all cardiac and noncardiac events during the same period (death, myocardial infarction, repeat revascularization procedures) will be assessed. Evaluating the efficacy of the procedure (symptomand event-free survival at 6 months: freedom from death, myocardial infarction, or repeat interventions) and monitoring changes in stenosis geometry immediately after stent implantation and at 6 months as assessed by quantitative coronary angiography will be secondary objectives.

The design of the current trial is to implant heparin- 


\section{BENESTENT Il}

coated stents in a stepped-care approach. The study consists of three phases in which a total of 150 patients will be treated with a single type of stent (50 patients in each phase). The interval from sheath removal to reinstituting heparin infusion will be 6 hours in the first, 12 hours in the second, and 24 hours in the third phase. Whether the study should proceed as planned from one phase to the next will be decided on the basis of a predetermined incidence of acute or subacute thrombotic stent occlusion. If there are three or more incidences of subacute thrombosis in phase I where heparin is resumed 6 hours after sheath removal, the study will be stopped. This number is derived from the $3.8 \%$ subacute thrombosis rate in the Benestent I trial. If there are less than three occlusions, progression of the trial to phase II will take place ( 12 hours without heparin) and if less than three occlusions occur in phase II, phase III will be entered where 24 hours will be allowed to relapse before restarting the heparin infusion.

Coumadin (Du Pont Pharmaceuticals, Wilmington, DE, USA), acetyl salicylic acid (250-mg daily), dipyridamol $75-\mathrm{mg}$ tid, and diltiazem $120-\mathrm{mg}$ bid, will be given as concomitant medication. Dextran will be given perioperatively and heparin will be administered according to the activated coagulation time.

If the course of phase III is successful, i.e., there are less than three subacute thrombotic occlusions, further steps in the pilot phase will be considered. The heparin-free interval may be prolonged to 48 hours or more, or the angiographic and clinical criteria may be widened, e.g., allowing implantation in vessels $<3 \mathrm{~mm}$ and in patients with unstable angina pectoris. Of course, the data obtained for other study parameters will have to be taken into account at that time. Therefore, this extension of the trial has not been planned in detail.

\section{Summary and Conclusions}

It has been shown repeatedly in animal and clinical studies that heparin coating reduces thrombotic complications of several surfaces in contact with flowing blood. The demonstration that implantation of heparincoated coronary stents is also effective in prevention of subacute thrombotic occlusion in a pig model offers the perspective of a clinical role of this treatment too. In order to put this to the test, the Benestent II pilot trial has been designed. This study will be conducted in a stepwise fashion in order to explore the feasibility of delaying deep anticoagulation as much as possible. Therefore, the primary goal is to minimize or exclude the need for heparin treatment following stent implantation. In addition, the effects on the need for revascularization procedures during follow-up will be recorded as well as the late morphological consequences as measured with quantitative coronary angiography.

\section{Appendix}

Benestent Study Group: Investigators and CoInvestigators.

1. San Carlos, Madrid-C. Macaya, J. Goicolea, F. Alfonso, A. Iniguez, Fernandez, Herena, Diaz, R. Berau.

2. Thoraxcenter, Rotterdam-P.W. Serruys, P. de Jaegere, P. de Feyter, M. van den Brand, M-A. Morel.

3. OLVG, Amsterdam-F. Kiemeneij, J-P. Smedema, H. Swart, G-J. Laarman, T. Slagboom, R. van der Wieken.

4. Rudolf Virchov, Berlin-W. Rutsch

5. OLVZ, Aalst-G. Heyndrickx, B. de Bruyne, P. Goemare, Nellens.

6. Sahlgrenska, Göteborg-H. Emanuelsson, P. Albertsson, L. Ekström, S.R. Johansson.

7. Clinique Pasteur, Toulouse--J. Marco, J. Fajadet, S. Doucet, O. Bar, Diaz, Jordan.

8. Sart Tilman, Liège - V. Legrand.

9. La Citadelle, Liège-P. Materne, J. Boland.

10. Instituto Cardiovascular, Buenos Aires-J. Be-

lardi, R. Piraino, Berocal.

11. RBNHLB, London-U. Sigwart, N. Buller.

12. Columbus Hospital, Milano-A. Columbo, L. Maiello.

13. CHUV, Lausanne-J. Goy, E. Eeckhout.

14. Middelheim, Antwerp-P. van den Heuvel, F. van den Branden.

15. Gregorio Maranon, Madrid-J. Delcan, L. Garcia.

16. De Weezenlanden, Zwolle-H. Suryapranata, J. Hoorntje.

17. St. Antonius, Nieuwegein-T. Plokker, G. Mast, Suttorp.

18. Ospitale Maggiore, Trieste-S. Klugmann, Della Grazia, A. Salvi.

19. Kantonale, Geneva-P. Urban, E. Camenzind. 
20. Acad. Ziekenhuis, Groningen-P. den Heijer. P. van Dijk.

21. AMC, Amsterdam-J. Piek, K. Koch.

22. Chris. Alb. University, Kiel-R. Simon, Herrmann.

23. CCN, St. Denis-M. Morice, T. Royer.

24. St. James, Dublin-P. Crean.

25. Catharina, Eindhoven-H. Bonnier, J. Koolen, F. Bracke, S. Roeffel, van Asperdt.

26. St. Luc. Brussels--W. Wijns, J. Renkin.

27. CHUR, Nancy - N. Danchin, Y. Yuillère.

28. Polyclinique Volney, Rennes-C. Bourdonnec, Descaves.

Note: "Bold names" = principal investigator.

\section{References}

1. Serruys PW. Beatt KJ, van der Giessen WJ. Stenting of coronary arteries: Are we the sorcerer's apprentice? Eur Heart J 1989:10(9):774-782.

2. Serruys PW. Strauss BH, van Beusekom HMM, et al. Pandora JACC 1991:17:143B-154B.

3. De Jaegere P. Macaya $C$. Kiemeneij F. et al. on behalf of the Benestent study group. Critical evaluation of the immediate angiographic results after stent implantation in the first 260 patients randomized in the Benestent Study. Circulation 1993 $88: 1-640$.

4. Garth W. Hastings (ed). Cardiovascular Biomaterials. London: Springer Verlag, 1992

5. Marcum JA, Rosenberg RD. Heparin-like molecules with anticoagulant activity are synthesized by cultured endothelial cells. Biochem Biophys Res Commun 1985;126:365-372

6. Awbrey B. Hoak IC. Owen WG. Binding of human thrombin to cultured human endothelial cells. J Biol Chem 1979;254: $+092-4095$

7. Lelah MD, Lambrecht LK, Cooper SL. A canine ex vivo series shunt experiment for evaluating thrombus deposition on polymer surfaces. J Biomed Mater Res 1984:18:475-496.

8. von Segesser LK. Turina M. Cardiopulmonary bypass without systemic heparinization. J Thorac Cardiovasc Surg 1989;98: 386-396.

9. Palanzo DA. Kunsz M, Butler BD. Surface tension effects of heparin coating on arterial line filters. Perfusion 1990;5: $277-284$.

10. Taylor KM. Discussion in von Segesser LK. Weiss BM. Gallino A. et al. Superior hemodynamics in left heart bypass without systemic heparinization. Eur J Cardiothorac Surg 1990:4: 384-389.

11. Li-Chien Hsu. Principles of heparin-coating techniques. Perfusion 1991:6:209-219.

12. Lindahl U. Bäckström G. Höök $M$. et al. Structure of the antithrombin-binding site in heparin. Proceedings of the National Academy of Sciences USA. 1979:76:3198-3202.

13. Thunberg L. Bäckström G, Lindahl U. Further characterization of the antithrombin-binding sequence in heparin. Carbohydr Res 1982:100:393-410

14. Pratt CW . Church FC. Antithrombin: Structure and function Semin Hematol 1991:28:3-9

15. Breckwoldt W' Beikin M Gould K. et al. Modification of the thrombogenicity of a self-expanding vascular stent. J Invest Surg 1991;4:269-278

16. Grode GA, Anderson SJ, Grotta HM, et al. Nonthrombogenic material via a simple coating process. Trans Am Soc Artif Organs 1969:15:1-5

17. Tanzawa H, Mori Y, Harumiya N, et al. Preparation and evaluation of a new antithrombogenic heparinized hydrophilic poly. mer for use in cardiovascular systems. Trans Am Soc Artif Intern Organs 1973;19:188-194

18. Jozefowicz M, Jozefowicz J. Heparin-containing and heparinlike polymers. In: Chiellini E, eds. Polymers in Medicine. New York: Plenum Press, 1986

19. Labarre D, Boffa MC, Jozefowicz M. Properties of heparinpoly(methyl methacrylate) copolymer. J Biomed Mater Res 1977;11:283-295

20. Miyama $\mathrm{H}$, Harumiya $\mathrm{N}$, Mori $\mathrm{Y}$, et al. A new antithrombogenic heparinized polymer. J Biomed Mater Res 1977;11: $251-265$.

21. Heyman PW, Cho CS, McRea JC, et al. Heparinized polyurethanes in vitro and ex vivo studies. J Biomed Mater Res 1985; 19:419-436.

22. Schmer $\mathrm{G}$. The biological activity of covalently immobilized heparin. Trans Am Soc Artif Intern Organs 1972;18:321-324

23. Finlay TH, Troll V, Hodgins LT. Immobilization of heparin with trichloro-s-triazine: Purification of mouse antithrombin. Anal Biochem 1980:108:354-359.

24. Goosen MFA, Sefton MV. Properties of heparin-polyvinylalcohol hydrogel coating. J Biomed Mater Res 1983;17: $359-373$.

25. Miyura Y. Aoyugi S, Kusada Y et al. The characteristics of anticoagulants by covalently immobilized heparin. J Biomed Mater Res 1980;14:619-630.

26. Larm $\mathrm{O}$, Larsson $\mathrm{R}$, Olsson $\mathrm{P}$. A new non-thrombogenic surface prepared by selective covalent binding of heparin via a modified reducing terminal residue. Biomat Med Dev Artif Organs 1983;11:161-163.

27. Hoffman AS, Schmer G, Harris C, et al. Covalent bonding of biomolecules to radiation-grafted hydrogels on inert polymer surfaces. Trans Am Soc Artif Inter Organs 1972;18:10-16.

28. Hoffman J, Larm O, Scholander E. A new method for covalent coupling of heparin and other glycosaminoglycans to substances containing primary amino groups. Carbohydr Res 1983:117:328-331.

29. Salzman EW, Rosenberg RDS, Smith MH, et al. Effect of heparin and heparin fragments on platelet aggregation. J Clin Invest 1980;65:64-73

30. Lagergren H, Olsson P, Swedenborg J. Inhibited platelet adhesion: A nonthrombogenic characteristic of a heparin coated surface. Surgery 1974:75:643-650.

31. Larsson $R$, Larm $O$, Olsson $P$. The search for thromboresistance using immobilized heparin. Ann N Y Acad Sci 1987; 516:102-115

32. Larm O, Larsson R. Olsson P. Surface-immobilized heparin. In: Lane DA, Lindahl U, eds. Heparin. Chemical and Biological Properties, Clinical Applications. London: Edward Amold Press. 1989, pp. 597-608

33. Reiber JHC, Semuys PW, Kooijman CJ, et al. Assessment of short-, medium-, and long-term variations in arterial dimensions from computer-assisted quantitation of coronary cineangiograms. Circulation 1985;71:280-288.

34. van der Giessen W, Hårdhammar $P$, van Beusekom MM, et al Reduction of thrombotic events using heparin-coated PalmazSchatz stents. 66th Scientific Sessions Georgia World Congress Center, Atlanta, 1993. Circulation 1993;88:I-661.

35. Hennink WE. Feijen J, Ebert CD, et al. Covalently bound conjugates of albumin and heparin. Synthesis, fractionation and characterization. Thromb Res 1993:29:1-13.

36. Vulic I, Pypers AP, Okano T, et al. Heparin-containing block copolymers. Part I: Surface characterization. J Mater Sic (Mater Med) 1993:4:353-365. 